\title{
Apple Inc. Analysis and Forecast Evaluation
}

\author{
Yunan Li* \\ Central University of Finance and Economics, Beijing 102206, China \\ *Corresponding author: Yunan Li, lyn200082@163.com
}

\begin{abstract}
Apple has been an American success story for quite a long time. After igniting the personal computer (PC) revolution in the 1970 s and reinventing PC in the 1980s, it again brought various innovative and game-changing products, including smartphones, computers, and wearables in recent years. Its dominant product, iPhone, sparked years of massive growth and has become the biggest drive of the company's success. Besides, with a market capitalization of more than $\$ 2 \mathrm{~T}$, Apple is currently the world's most valuable company. This makes many investors interested in AAPL stock. Hence, this paper will explore whether the APPL stock is worth investing based on the analysis of its business model, SWOT analysis, and relative valuation in hope to provide some recommendations and predictions for investors.
\end{abstract}

Keywords: Investment; SWOT analysis; Relative valuation

Publication date: August 2021; Online publication: August 30, 2021

\section{Company's business model}

Apple Inc. is an American multinational technology company that designs, manufactures, and markets mobile communication devices, computers, accessories, and other hardware components in addition to sell various related software and services. The company is known for its hardware products including iPhone, Mac, iPad, and online services like Apple Care and iCloud ${ }^{[1]}$.

Table 1 shows the company's total net sales and net income for 2020, 2019, and 2018.

Table 1. Apple's total net sales and net income for 2020, 2019, and 2018 (dollars in millions)

\begin{tabular}{cccc}
\hline Year & 2020 & 2019 & 2018 \\
\hline Total net sales & 274,515 & 260,174 & 265,595 \\
Net income & 57,411 & 55,256 & 59,531 \\
\hline
\end{tabular}

Table 2 shows the company's net sales by category, net sales by reportable segment, gross margin, and operating expenses for 2020 and 2019. 
Table 2. Apple's net sales by category, net sales by reportable segment, gross margin, and operating expenses for 2020 and 2019 (dollars in millions)

\begin{tabular}{clcc}
\hline & \multicolumn{1}{c}{ Year } & 2020 & 2019 \\
\hline & iPhone & 137781 & 142381 \\
\multirow{2}{*}{ Net sales by } & Mac & 28622 & 25740 \\
category & iPad & 23724 & 21280 \\
& Wearables, home, and accessories & 30620 & 24482 \\
& Services & 53768 & 46291 \\
\hline \multirow{2}{*}{ Net sales by } & Americas & 124556 & 116914 \\
reportable segment & Europe & 68640 & 60288 \\
& Jreater China & 40308 & 43678 \\
& Japan & 21418 & 21506 \\
& Rest of Asia Pacific & 19539 & 17788 \\
\hline \multirow{2}{*}{ Gross margin } & Products & $31.5 \%$ & $32.2 \%$ \\
percentage & Services & $66.0 \%$ & $63.7 \%$ \\
& Total gross margin & $38.2 \%$ & $37.8 \%$ \\
\hline Operating expenses & Research and development & $18752(7 \%)$ & $16217(6 \%)$ \\
and percentage & Selling, general, and administrative & $19916(7 \%)$ & $18245(7 \%)$ \\
\hline
\end{tabular}

Apple's total net sales and net income decreased from 2018 to 2019, but then it increased from 2019 to 2020. During the fiscal year 2020, the company gained a total net sale of $\$ 274,515$ million, exceeding that in 2018, and a net income of $\$ 57,411$ million. These fluctuations could have been occasioned by several factors including changes in macroeconomic conditions, the company's service structures, warranty policies, foreign exchange fluctuations, etc.

The company's net sales by category showed that more than half of the total net sales came from iPhone. However, the net sales of iPhone decreased by 3\% from 2019 to 2020, which could be attributed to the absence of new iPhone models in the fourth quarter of 2020. The weakening of foreign currencies relative to the U.S. dollar could also have reduced the demand for the company's products in some foreign markets and adversely affected the U.S. dollar value of the revenue. Thanks to the high net sales of AirPods and Apple Watch, there was a significant growth in the net sales under the category of "Wearables, Home, and Accessories."

The company's gross margin percentage in services was dramatically larger than that in its product profits. While the product gross margin percentage was $31.5 \%$ in 2020, the service gross margin percentage reached to $66 \%$. It means that each dollar of added service sales disproportionately boosted Apple's profits compared to hardware sales. To bolster its service sales, the company had introduced a large number of new and updated services, including the company's digital content stores and streaming services, such as App Store platforms, Apple Music, and Apple TV+. It also generated revenue from Apple Care, licensing, and other services, including Apple Card and Apple News. Apple is increasingly seen not just as a hardware company but a major player in the software business.

The company's reportable segments consist of America, Europe, Greater China, Japan, and the rest of Asia Pacific. During 2020, Greater China was the only segment where net sales declined compared to 2019. It decreased by $8 \%$ to $\$ 40,308$ million because of the weakness in RMB relative to U.S. dollar and lower net sales of iPhone in China. Still, the net sales of service and iPad in China went up in 2020, possibly driven by the growing demands for remote work and course under the background of the COVID-19 pandemic. 
During 2020, the company spent $7 \%$ of its total net sales on research and development (R\&D), and another $7 \%$ on selling, general, and administrative purposes. Since the development of updated devices and services are central to Apple Inc.'s business strategy, the company continues to focus investments in R\&D to strengthen its competitive position in the market. The year-over-year growth in R\&D expense increased by $16 \%$ compared to 2019 , which was primarily driven by the increased in headcount-related expenses.

To sum up, Apple has adequate financial strength, but it is currently suffering from fluctuation. It is not likely to record higher net sales or income year-over-year. However, it is understood that Apple is working hard on breaking this bottleneck by investing more in research and product development. In addition, there would be significant change in the company's business strategy. Although iPhone has long been the dominant product of the company, service and wearables will become the next big growth driver for the company in the near future since the iPhone business maturing and its sales slowed down.

\section{Industry analysis}

\subsection{Top competitors}

Table 3. Top competitors of Apple

\begin{tabular}{ccccc}
\hline Business lines & iPhone & Mac & iCloud & Streaming service \\
\hline Competitors & Samsung & Lenovo & Microsoft & Amazon \\
& Huawei & HP & Amazon & Disney \\
& Pixel (Google) & Dell & Dropbox & Netflix \\
& LG & Asus & Google & Warner \\
& Xiaomi & Acer & Box. & Sony \\
& Motorola & Sony & Citrix & \\
\hline
\end{tabular}

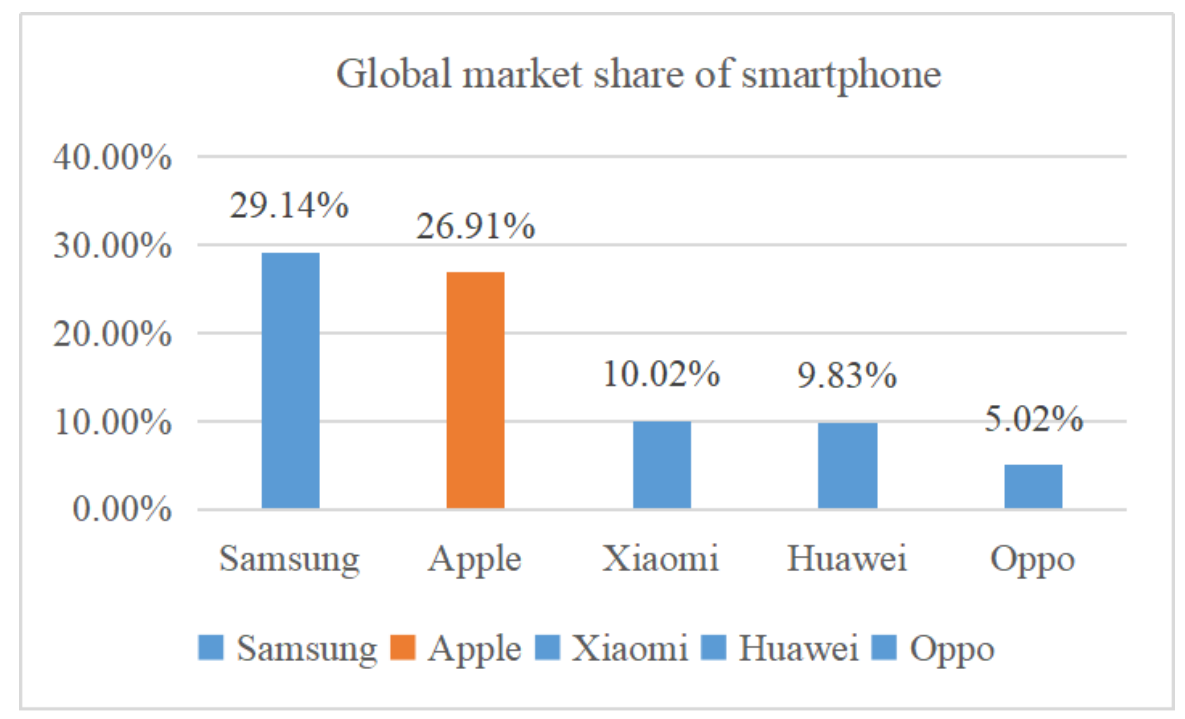

Figure 1. Global market share of smartphone

In the U.S. smartphone market, Apple had a market share of $61.07 \%$ in 2020, which makes it the dominant market leader. Its closest competitors in the country are Samsung, LG, Motorola, and Google (Pixel) ${ }^{[2]}$. However, it faces strong competition in the global market. With $26.91 \%$ global market share, it was positioned as the second largest smartphone company behind Samsung whose market share was 
29.14\% (Figure 1). In fact, Samsung competes with Apple in almost all divisions and has maintained between $20 \%$ to $30 \%$ shares in the smartphone market since $2012^{[2]}$.

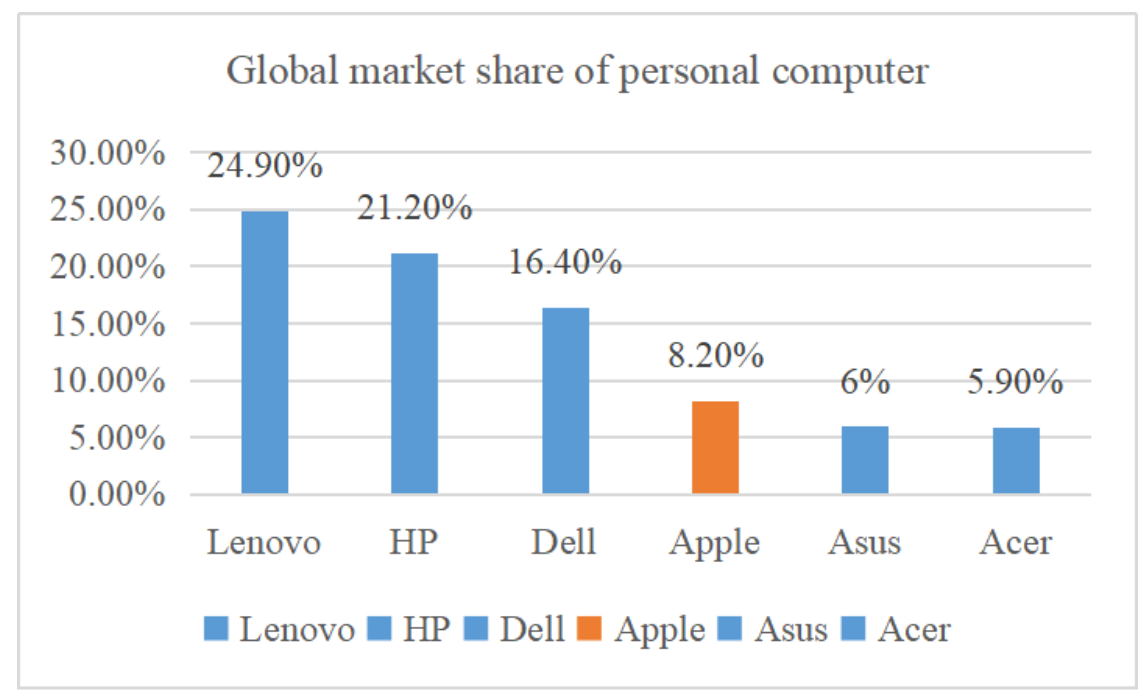

Figure 2. Global market share of personal computer

Apple has made impressive progress in the personal computer market and became the 4th most sold computer company with $8.2 \%$ global market share ${ }^{[3]}$. However, it is still unlikely that it would be one of the top three in the near future. Its main competitors are Lenovo, HP Inc., Dell, Asus, and Acer with 24.9\%, $21.2 \%, 16.4 \%, 6 \%$, and $5.9 \%$ market share, respectively ${ }^{[4]}$ (Figure 2).

As for the cloud storage service market, Dropbox has long been one of iCloud's top competitors. This information technology (IT) service company generates 2,062\% of iCloud's revenue (Table 3).

Netflix and Amazon are considered the runaway leaders in the streaming media market with over 158 million subscribers of Netflix in 190 countries and over 100 million people signed up for Amazon's service. Both Disney and Apple having launched their own subscription services in recent years. While Disney is estimated to have 82 million subscribers by 2024 , equal to about $8 \%$ of the market, Apple is only expected to remain a bit player with less than $1 \%$ (Table 3).

\subsection{SWOT analysis}

The SWOT analysis framework is a strategic management decision-making tool that determines the most pressing issues faced by the company based on internal business conditions and external environment. SWOT stands for strengths, weaknesses, opportunities, and threats. 


\section{Strengths}

Strengths are internal factors specific to the conditions within a business organization and its technological capabilities. This section identifies the strengths that enable Apple to overcome its weaknesses, take advantage of its opportunities, and withstand threats in its business environment.

\section{- Valuable brand and global icon}

Apple is one of the most famous companies when it comes to personal computer and smart technology devices. According to the Best Global Brands 2020 ranking, it is the most valuable brand with an estimated value of almost $\$ 323$ billion. It also has millions of loyal customers with a steady increment.

\section{- Rapid innovation}

Apple is capable of introducing innovative products and is determined to develop more high-end technology devices. The company always keeps abreast with the latest technologies, which ensures its competency in the market.

\section{- Expansion in services}

Apple shows dedication in expanding its services portfolio and has successfully introduced various services including iCloud, AppleCare, Apple Card, etc. In FY2020, 19\% of its revenue came from it services, which is second to the revenue from iPhone $(50 \%)$.

\section{Opportunities}

Opportunities are external factors based on the industry environment. This part of analysis pinpoints the most significant opportunities which are available to the business.

\section{- Expansion of distribution network}

As e-commerce is expected to grow significantly for the next decade, Apple has the opportunity to expand its distribution network and reach more customers in the global market.

\section{- Potential in smart wearable market}

According to the industry analyst, CCS Insight, worldwide smart wearable device sales would double by 2022 , becoming a $\$ 27$ billion+ market with 233-million-unit sales ${ }^{[1]}$. Apple could kick-start this device category by adding more functions to its AirPods and Apple Watch, and even expand into other wearable categories.

\section{- $\quad$ Rising demand for mobile products}

The rising dependence of mobile access and digital systems has led to a higher demand for technological devices. The company has the opportunity to grow its sales volume and revenue through aggressive marketing, especially for mobile products like iPhone and iPad.

\section{Weaknesses}

Weaknesses are internal factors that are obstacles to business growth in consideration of the performances of other technology businesses. In this aspect of the SWOT analysis, the emphasis is on the weaknesses or inadequacies of Apple.

\section{- High prices}

Due to Apple's premium pricing, its products sometimes can be considered as luxuries, which only middle and high-class consumers can afford.

\section{- Limited advertisement and promotions}

Instead of excessively spending on advertisements or promotions, Apple relies heavily on its icon and flagship retail stores. It has limited advertising resources, but it solidifies its ground primarily by maintaining loyal customers.

\section{- Incompatibility with other software}

Apple's products do not support other software or system, making them incompatible with other devices. Customers have to exclusively purchase Apple apps or accessories to continue using their products. As a result, some customers may choose other brands to avoid this inconvenience at the very beginning.

\section{Threats}

Threats are external factors that limit or reduce the financial performance of a business. In this analysis, the focus is on the threats that the company experiences from various sources.

\section{- Aggressive competition}

Brands like Google, Samsung, and Dell are tough competitions for Apple with their rapid innovation and advanced technology. In addition, some local firms in foreign countries imitate the design and features of Apple's products and compete based on lower prices. The aggressive competition has a limiting effect on the company's business, indicating the necessity for strong fundamentals for maintaining competitive advantages in software, hardware, and online services.

\section{- Rising labor costs}

The rising labor costs in many countries where Apple facilities are located would affect the company's revenue and may force the company to increase the selling prices.

\section{- Coronavirus outbreak}

The measures taken by many countries in response to the COID-19 pandemic have affected and could adversely impact the company's business in the future, including the results of operations, financial condition, and stock price.

Figure 3. SWOT analysis 
The principle block diagram of the this SWOT analysis of Apple Inc. presents the strategic factors that influence the decisions of the chief executive officer (CEO), Tim Cook, and the managers in developing the business. It can be seen that Apple Inc.'s success is linked to the ability to use business strengths to overcome weaknesses and threats, as well as to exploit opportunities in the industry environment. Internal factors such as high prices, and external factors including competition and macroeconomic negatively affect its technological product development and marketing capabilities. Hence, Apple needs to seek for innovative products and services in crossing the hurdle. In order to seize the opportunity of potential market, the company must ensure effective management, consumer acceptance, timely introduction of new technology, and the availability of the required components ${ }^{[5]}$ (Figure 3).

\subsection{Relative valuation}

The price-to-earnings ratio ( $\mathrm{P} / \mathrm{E}$ ratio) is the ratio in valuing a company that measures its current share price relative to its earnings per-share (EPS). It is often used to estimate the relative value of a company's share in comparing apples to apples. Companies that have no earnings or that are losing money do not have a P/E ratio since there is nothing to propose as the denominator ${ }^{[6]}$. The formula used for this process are as follows:

$$
P / E \text { Ratio }=\frac{\text { Market value per share }}{\text { Earnings per share }(E P S)}
$$

Two kinds of $\mathrm{P} / \mathrm{E}$ ratios, trailing and forward $\mathrm{P} / \mathrm{E}$, are used in practice. The trailing $\mathrm{P} / \mathrm{E}$ relies on past performance by dividing the current share price by the total EPS earnings over the past 12 months. It is the most popular P/E metric because it is objective and accurate. The forward P/E uses the guidance of future earnings rather than trailing figures. This forward-looking indicator is more useful in comparing current earnings to future earnings which helps provide a clearer picture of what the earnings would look like in the near future.

Another important indicator, price/earnings to growth ratio (PEG ratio), is a stock's price-to-earnings $(\mathrm{P} / \mathrm{E})$ ratio divided by the growth rate of its earnings for a specified time period. It is used to determine a stock's value while also factoring in the company's expected earnings growth. The calculation work is as follows:

$$
P E G \text { Ratio }=\frac{P / E \text { Ratio }}{\text { Growth rate in EPS }}
$$

The lower the PEG ratio, the more the stock may be undervalued; given its future earnings expectations. 
Table 4. PE ratio and PEG ratio of Apple Inc. and its main competitors

\begin{tabular}{|c|c|c|c|c|}
\hline \multicolumn{2}{|c|}{ Company } & Trailing P/E ratio & Forward $\mathrm{P} / \mathrm{E}$ ratio & PEG ratio (5-year expected) \\
\hline \multicolumn{2}{|c|}{ Apple } & 35.27 & 30.58 & 2.9 \\
\hline \multirow{6}{*}{$\begin{array}{l}\text { iPhone } \\
\text { competitors }\end{array}$} & Samsung & 22.28 & 15.11 & 1.02 \\
\hline & Google & 36.31 & 31.25 & 1.51 \\
\hline & $\mathrm{LG}$ & / & 10.71 & I \\
\hline & Xiaomi & 41.8 & 38.76 & 1.54 \\
\hline & Motorola & 33.22 & 21.05 & 1.87 \\
\hline & Average & 33.78 & 24.58 & 1.77 \\
\hline \multirow{6}{*}{$\begin{array}{c}\text { Mac } \\
\text { competitors }\end{array}$} & Lenovo & 20.47 & 14.27 & 2.79 \\
\hline & Dell & 25.25 & 11.53 & 2.19 \\
\hline & HP & 13.74 & 10.3 & 1.28 \\
\hline & Asus & 11.53 & 11.48 & I \\
\hline & Sony & 13.76 & 22.62 & 2.75 \\
\hline & Average & 16.95 & 14.04 & 2.25 \\
\hline \multirow{7}{*}{$\begin{array}{c}\text { iCloud } \\
\text { Competitors }\end{array}$} & Microsoft & 36.32 & 33.22 & 2.47 \\
\hline & Amazon & 79.1 & 64.52 & 1.57 \\
\hline & Dropbox & 129 & 24.04 & 0.91 \\
\hline & Google & 36.31 & 31.25 & 1.51 \\
\hline & Box. & l & 25.51 & I \\
\hline & Citrix & 27.98 & 20.28 & 1.82 \\
\hline & Average & 61.74 & 33.14 & 1.66 \\
\hline \multirow{6}{*}{$\begin{array}{l}\text { Streaming } \\
\text { service } \\
\text { competitors }\end{array}$} & Amazon & 79.1 & 64.52 & 1.57 \\
\hline & Disney & 51.22 & 104.17 & 3.44 \\
\hline & Netflix & 90.68 & 56.5 & 2.52 \\
\hline & Warner & 94.47 & 54.47 & 2.40 \\
\hline & Sony & 13.76 & 22.62 & 2.75 \\
\hline & Average & 65.846 & 60.456 & 2.536 \\
\hline Overall market & S\&P 500 Index & 44.94 & 25.35 & I \\
\hline
\end{tabular}

Compared to the smartphone and personal computer markets, Apple have higher trailing and forward $\mathrm{P} / \mathrm{E}$ ratios, which means that the company's stock is overvalued, or the investors are expecting high growth rates in the future. In terms of cloud storage, streaming service, and even in the whole market, Apple's stock is underestimated and worth purchasing due to its lower P/E ratios. However, Samsung, Apple's main competitor in the smartphone market, has the lowest $\mathrm{P} / \mathrm{E}$ ratio in this area, which makes it a perfect alternative to Apple (Table 4).

Since another two strong competitors, Google and Microsoft, have similar P/E ratios with Apple, PEG ratio is added as another indicator for further comparison. Adding a company's expected growth into the ratio helps to adjust the result for companies that may have a high growth rate and $\mathrm{P} / \mathrm{E}$ ratio. According to an investor, Peter Lynch, a company's P/E and expected growth should be equal which denotes a fairly valued company and supports a PEG ratio of 1.0. When a company's PEG exceeds 1.0, it is considered overvalued whereas a stock with a PEG of less than 1.0 is considered undervalued. The latter situation only occurred to Dropbox among the listed companies, which indicates that Apple and all the other competitors are overvalued (Table 4). 
When looking at Apple, Google, and Microsoft, one might find Apple's stock more attractive at first due to its slightly lower P/E ratio. However, Apple has a higher PEG ratio, which means it does not have a high enough growth rate to justify its P/E. On the other hand, Google is trading at a discount to its growth rate, and investors purchasing it are paying less per unit of earnings growth (Table 4).

\section{Conclusion}

In conclusion, although owning an outstanding market value and cutting-edge technologies, Apple is facing critical risk factors that could adversely affect its sales and ultimately, its profitability. On the whole, it is not recommended to purchase Apple's stock for investors who are interested in this stock.

For one thing, the increasing prices of Apple products and the intensive competition in the market are causing much more pressure on this company, and the impact of some black swan events like COVID-19 should be taken into consideration. These are actually external factors that are not able to be controlled or predicted by the company. Hence, nobody can guarantee that Apple could seize all opportunities and remove all the threats in generating more revenue. For another, there actually lies a better choice. Samsung, the strong competitor of Apple in many divisions, and also the one who had beat iPhone in the global smartphone market, has both lower P/E ratio and PEG ratio compared to Apple. This would make Samsung's stock a wiser buy.

\section{Disclosure statement}

The author declares that there is no conflict of interest.

\section{References}

[1] 2020, Apple Inc, Form 10-K, 1, 21-3.

[2] Statcounter, 2021, Mobile Vendor Market Share Worldwide. https://gs.statcounter.com/vendor-marketshare/mobile

[3] Holst A, 2021, Market Share Held by the Leading Personal Computer Vendors Worldwide in 2018.

[4] Alsop T, 2021, Global market share held by PC vendors 2006-2020. Statisca. https://www.statista.com/ statistics/267018/global-market-share-held-by-pc-vendors/

[5] Lambkin P, 2018, Smart Wearables Market to Double By 2022: \$27 Billion Industry Forecast. Forbes. https://www.forbes.com/sites/paullamkin/2018/10/23/smart-wearables-market-to-double-by-2022-27 -billion-industry-forecast/?sh=41869de02656

[6] California State University Long Beach, 2020, The Peter Lynch Approach to Investing in 'Understandable' Stocks (accessed on 8/5/2020). 